\title{
Identifying block rotations from remanent magnetization effect: Example from northern Central Turkey
}

\author{
Funda Bilim ${ }^{1}$ and Abdullah Ates ${ }^{2}$ \\ ${ }^{1}$ Cumhuriyet University, Faculty of Engineering, Department of Geophysical Engineering, 58140, Sivas, Turkey \\ ${ }^{2}$ Ankara University, Faculty of Engineering, Department of Geophysical Engineering, 06100, Besevler, Ankara, Turkey
}

(Received November 28, 2005; Revised July 31, 2006; Accepted August 1, 2006; Online published March 15, 2007)

\begin{abstract}
One of the difficulties in interpreting magnetic anomaly data is the distortion caused by rock body magnetization. There have been several successful studies carried out on the estimation of body magnetization based on the correlation of the Bouguer and magnetic anomaly data. A number of other significant research projects have aimed at identifying the effect of remanent magnetization in magnetic data only. In this paper, we present a threedimensional method for determining the body magnetization direction by means of comparing the amplitude of the analytic signal with the horizontal gradient of pseudogravity of magnetic anomaly using the correlation coefficient equation. The method has been successfully applied to test cases and is applied here to the aeromagnetic anomalies located in northern Central Turkey. Anomalies displaying individual polarities were separated out and correlated with themselves using the correlation coefficient equation. Counter-clockwise rotations in the range of $3^{\circ}$ and $174^{\circ}$ were determined. Clockwise rotations were determined in the range of $19^{\circ}$ and $153^{\circ}$. The inclination of the body magnetization directions for one of the blocks was estimated to be $68.4^{\circ}$, while all other blocks had a low inclination angle of body magnetization in the range of $32^{\circ}$ to $57^{\circ}$. These results may imply that these blocks gained their magnetizations when Turkey was at low latitudes. Possible buried faults are also identified. The results reported here comply with the new mobilistic theory.
\end{abstract}

Key words: Magnetic anomaly, correlation coefficient function, northern Central Anatolia, block rotation, buried faults.

\section{Introduction}

One of the earliest and significant studies aimed at identifying the remanent magnetization direction was published by Zeitz and Henderson (1956), who interpreted the shape of the anomalies to estimate the body magnetization. Baranov (1957) subsequently was the first to obtain the transformation of pseudogravity by converting magnetic anomalies into (pseudo)-gravity anomalies. This conversion is important as a means to estimate the direction of body magnetization correctly to produce a successful transformation.

Roest et al. (1992) interpreted magnetic anomalies using the three-dimensional analytical signal and suggested that the analytical signal defines the outlines of the magnetic sources. Roest and Pilkington (1993) proposed a method for estimating the direction of magnetization; however, because of the non-uniqueness of magnetic modelling, additional constraints were needed. Consequently, they crosscorrelated the analytical signal, which is assumed to show edges of the source body, with the horizontal pseudogravity gradient. The reduction to pole, with the correct angle of the body magnetization, was transformed into the horizontal derivative of pseudogravity, producing a satisfactory result. The estimated body magnetization was later used by Blakely and Simpson (1986) to obtain three-dimensional

Copyright (c) The Society of Geomagnetism and Earth, Planetary and Space Sciences (SGEPSS); The Seismological Society of Japan; The Volcanological Society of Japan; The Geodetic Society of Japan; The Japanese Society for Planetary Sciences; TERRAPUB. maxima of the horizontal gradient of pseudogravity map. Bilim and Ates (1999) correlated the Bouguer and pseudogravity anomaly data of the same area to estimate the magnetization direction. Their method was sensitive to the ratio of density to magnetization $(\rho / J)$. Recently, Bilim and Ates (2004) further improved their earlier method using Meyer's (1965) correlation coefficient equation $(r)$. The correlation was not sensitive to the density to magnetization ratio $(\rho / J)$, and the synthetic examples demonstrated a successful estimation of magnetization direction.

In this paper, we used Meyer's (1965) correlation coefficient equation $(r)$ for the three-dimensional magneticto-magnetic correlation. Hence, the analytic signal was correlated with the horizontal derivative of pseudogravity. Test cases demonstrated a successful estimation of the direction of body magnetization. The application of this method to the aeromagnetic anomalies of northern Central Turkey in a faulted area demonstrated both clockwise and counter-clockwise block rotations and the possibility of buried faults. Most of the blocks displayed a low inclination angle of body magnetization, which could be indicative of a northwards drift of Turkey following the acquisition of magnetization.

The anticlockwise rotation of Turkey is well documented. Sanver and Ponat (1981) suggested a $90^{\circ}$ anticlockwise rotation of the Kirsehir Block based on palaeomagnetic data, and Rotstein (1984) made a similar suggestion based on tectonic and seismological studies. McClusky et al. 


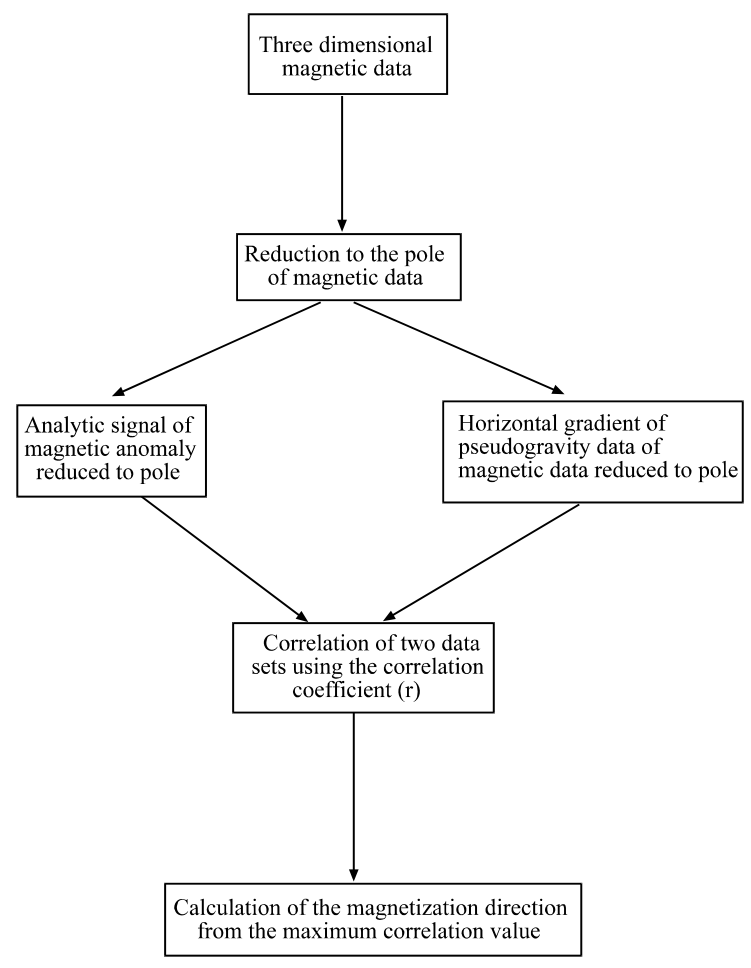

Fig. 1. Steps of the method summarized in a simplified diagram.

(2000) recently demonstrated anticlockwise rotation and the westward movement of the Anatolia based on GPS measurements. In addition, a number of other studies have demonstrated both anticlockwise rotation and occurrences of clockwise rotations. These studies include those of Saribudak et al. (1990), who demonstrated clockwise rotation of the Almacik Flake, northwest of Turkey, based on palaeomagnetic studies, and Piper et al. (2002), who suggested both the anticlockwise rotation of the Cappadocia, Central Turkey, as well as the clockwise rotation of the western extremity of Cappadocia, based on palaeomagnetic data. The analysis of aeromagnetic anomalies of the Cappadocia by Büyüksarac et al. (2005) also indicated both anticlockwise and clockwise rotations. Anatolia was in this collision zone and at the centre of a strained location. The opposite directions of rotations of the microblocks can thus be well correlated with the new mobilistic theory described by Storetvedt (2003) and we explain here our results in terms of a new theory called the "mobilistic system" (Storetvedt, 2003).

\section{The Method}

The method proposed in this paper is similar to that proposed by Roest and Pilkington (1993) who determined the direction of magnetization using the cross correlation of the analytic signal with the horizontal derivative of the pseudogravity of magnetic data. Their method is sensitive to the magnetization declination.

The correlation coefficient equation $(r)$ of Meyer (1965) has recently been used to determine the direction of body magnetization from the Bouguer and magnetic anomaly data (Bilim and Ates, 2004). In this paper, we used Meyer's correlation coefficient equation $(r)$ to correlate the three-

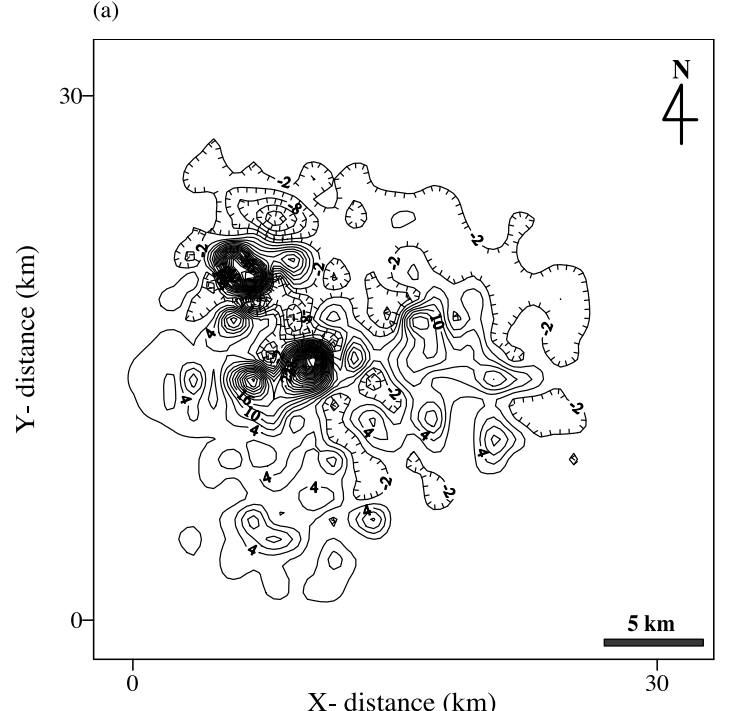

(b)

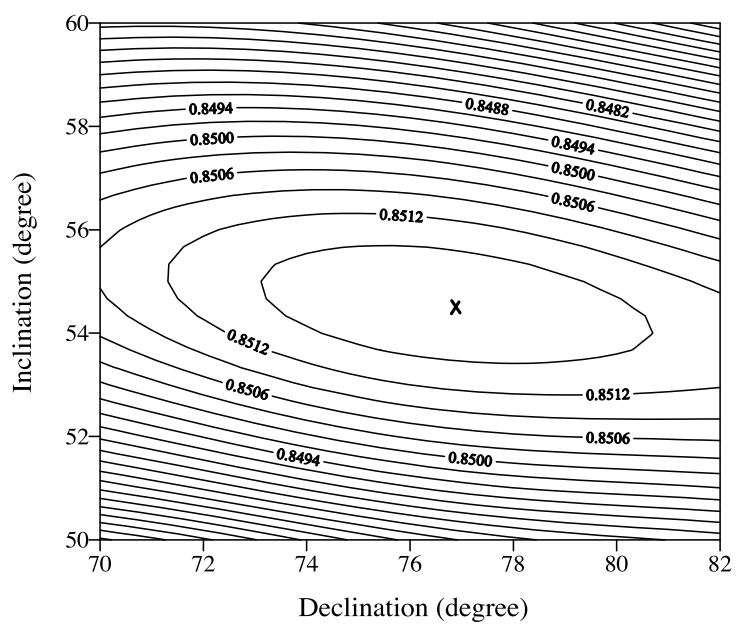

Fig. 2. (a) Magnetic anomaly map with $7 \%$ in terms of $32 \mathrm{~km}(\mathrm{X}=\mathrm{Y}$ distance) random error, (b) contour map of correlation coefficient $(r)$ of Fig. 7(a).

dimensional analytic signal and the horizontal derivative of the pseudogravity of magnetic data.

Meyer's (1965) correlation coefficient equation $(r)$ is:

$$
r=\frac{c}{d}
$$

where

$$
\begin{aligned}
c & =c 1-c 2 \\
d & =d 1 * d 2 \\
c 1 & =n \times m \sum_{i=1}^{n} \sum_{j=1}^{m} G(i, j) P(i, j) \\
c 2 & =\sum_{i=1}^{n} \sum_{j=1}^{m} G(i, j) \sum_{i=1}^{n} \sum_{j=1}^{m} P(i, j) \\
d 1 & =\sqrt{n \times m \sum_{i=1}^{n} \sum_{j=1}^{m} G(i, j)^{2}-\left(\sum_{i=1}^{n} \sum_{j=1}^{m} G(i, j)\right)^{2}} \\
d 2 & =\sqrt{n \times m \sum_{i=1}^{n} \sum_{j=1}^{m} P(i, j)^{2}-\left(\sum_{i=1}^{n} \sum_{j=1}^{m} P(i, j)\right)^{2}} .
\end{aligned}
$$


Table 1. Parameters of synthetic model.

\begin{tabular}{cccccccccccc}
\hline Body & $x_{t}$ & $x_{b}$ & $y_{t}$ & $y_{b}$ & $h_{t}$ & $h_{b} \begin{array}{c}D_{0} \\
\text { (degree) }\end{array}$ & $\begin{array}{c}I_{0} \\
\text { (degree) }\end{array}$ & $\begin{array}{c}D_{b} \\
\left(\mathrm{~A} \cdot \mathrm{m}^{-1}\right)\end{array}$ \\
\hline 1 & 8 & 10 & 17 & 19 & 1 & 4 & 4 & 55 & 80 & 50 & 1 \\
2 & 10 & 12 & 8 & 10 & 2 & 3 & 4 & 55 & 80 & 50 & 1 \\
3 & 19 & 20 & 13 & 19 & 2 & 3 & 4 & 55 & 80 & 50 & 1 \\
\hline
\end{tabular}

$x_{t}$ and $x_{b}=$ Extension of model from $\mathrm{x}$ to $\mathrm{x}$ in the $\mathrm{X}$ direction. $y_{t}$ and $y_{b}=$ Extension of model from $\mathrm{y}$ to $\mathrm{y}$ in the $\mathrm{Y}$ direction. $h_{t}=$ Top of model. $h_{b}=$ Bottom of model. $I_{0}=$ Inclination of geomagnetic field. $D_{0}=$ Declination of geomagnetic field. $I_{b}=$ Inclination of a body magnetization. $D_{b}=$ Declination of a body magnetization. $J=$ Intensity of magnetization.

where $r$ is the correlation coefficient, $G(i, j)$ is the analytic signal, $P(i, j)$ is the horizontal derivative of the pseudogravity transformation of the magnetic anomalies, and $n$ and $\mathrm{m}$ are the number of points in the $\mathrm{X}$ and $\mathrm{Y}$ spatial directions, respectively. The method searches for the maximum correlation between these two data sets that have been transformed from magnetic anomalies. Steps of the method are summarized given below and depicted in a simplified diagram in Fig. 1.

\subsection{Reduction to the pole}

If the magnetization and ambient field are not vertical, magnetic anomalies are not located over the sources of the magnetic anomalies, thereby causing distortion in the shape of magnetic anomaly. Reduction to the pole (RTP) transformation reproduces the magnetic field of the causative body as if it was at the magnetic pole, whereas the magnetization and ambient field would be vertical (Blakely, 1995). After RTP transformation, magnetic anomalies are centered on the sources symmetrically. The RTP transformation equation in the Fourier domain is given by Blakely (1995) as:

$$
F\left[\Delta T_{r}\right]=F\left[\psi_{r}\right] F[\Delta T],
$$

where

$$
\begin{aligned}
F\left[\psi_{r}\right] & =\frac{|k|^{2}}{a_{1} k_{x}^{2}+a_{2} k_{y}^{2}+a_{3} k_{x} k_{y}+i|k|\left(b_{1} k_{x}+b_{2} k_{y}\right)}, \\
|k| & \neq 0,
\end{aligned}
$$

where $F=$ the Fourier transformation; $\Delta T_{r}=$ the RTP anomaly; $\Delta T=$ the magnetic anomaly; $\mathbf{k}=\left(i k_{x}, i k_{y},|k|\right)$ $; \hat{m}=\left(\hat{m}_{x}, \hat{\mathbf{m}}_{y}, \hat{m}_{z}\right)$ and $\hat{\mathbf{f}}=\left(\hat{f}_{x}, \hat{f}_{y}, \hat{f}_{z}\right)=$ unit vectors in the direction of the magnetization and in the direction of the ambient field, respectively; $a_{1}=\hat{m}_{z} \hat{f}_{z}-\hat{m}_{x} \hat{f}_{x}, a_{2}=$ $\hat{m}_{z} \hat{f}_{z}-\hat{m}_{y} \hat{f}_{y}, a_{3}=-\hat{m}_{y} \hat{f}_{x}-\hat{m}_{x} \hat{f}_{y}, b_{1}=\hat{m}_{x} \hat{f}_{z}+\hat{m}_{z} \hat{f}_{x}$, $b_{2}=\hat{m}_{y} \hat{f}_{z}+\hat{m}_{z} \hat{f}_{y}$.

\subsection{Pseudogravity transformation}

The magnetic anomaly is converted into the gravity anomaly with respect to Poisson's relation (Baranov, 1957). The relationship between pseudogravity $\left(g_{p}\right)$ and magnetic potential $(V)$ in the Fourier domain is given by

$$
F\left[g_{p}\right]=\frac{B}{\left(\hat{m}_{z}+i \frac{\hat{m}_{x} k_{x}+\hat{m}_{y} k_{y}}{|k|}\right)} F[V]
$$

(Blakely, 1995). Where $B$ is a constant.

\subsection{Analytic signal}

The analytic signal is formed by the horizontal and vertical gradient of the magnetic anomaly. In the three-

\section{(a)}

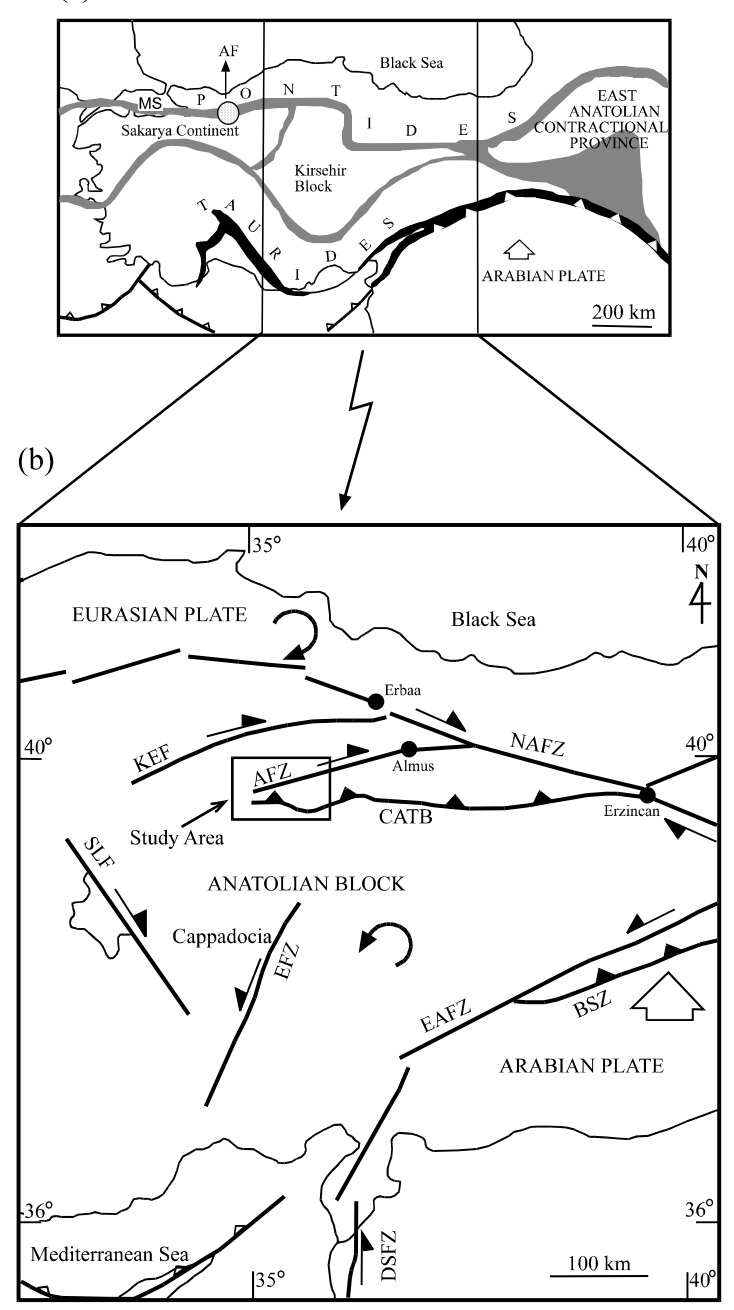

Fig. 3. (a) Simplified major tectonic divisions of Turkey. MS: Marmara Sea; AF: Almacik Flake, (b) the tectonic division and distribution of major lineaments in Central Turkey. The large open arrow shows relative motion of the Arabian plate. The smaller half arrows show the directions of movement on major strike-slip faults. NAFZ: North Anatolian Fault Zone; EAFZ: East Anatolian Fault Zone; SLF: Salt Lake Fault; KEF: Kirikkale-Erbaa Fault; AFZ: Almus Fault Zone; EFZ: Ecemis Fault Zone; CATB: Central Anatolian Thrust Belt; DSFZ: Dead Sea Fault Zone (modified from GURSOY et al., 1998).

dimensional case, the analytic signal is given by

$$
\mathbf{A}(x, y)=\frac{\partial T}{\partial x} \hat{\mathbf{i}}+\frac{\partial T}{\partial y} \hat{\mathbf{j}}+i \frac{\partial T}{\partial z} \hat{\mathbf{k}} .
$$

Where, $\hat{i}, \hat{j}$, and $\hat{k}$ are the unit vectors in the $x, y, z$ directions, respectively. $T$ is the magnetic anomaly. From 


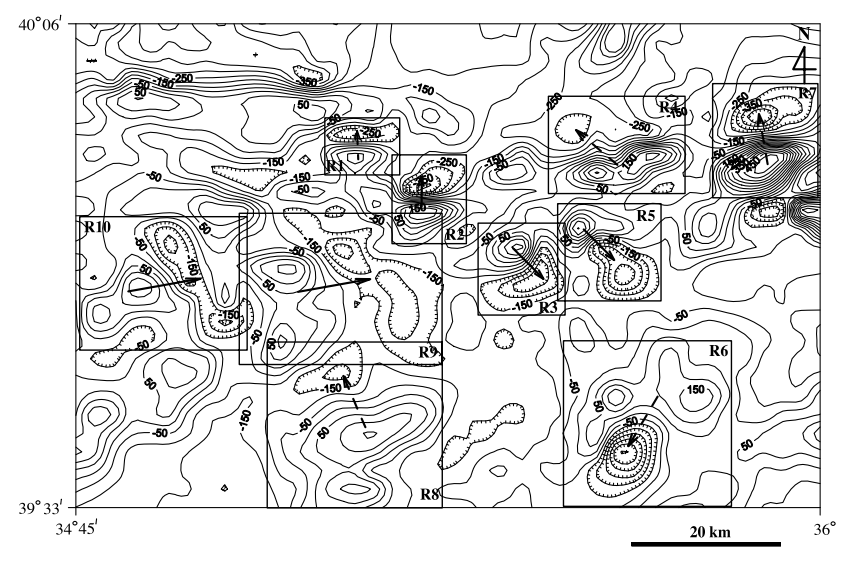

Fig. 4. The residual total aeromagnetic anomaly map of the study region in northern Central Turkey. Contour interval is $50 \mathrm{nT}$. Solid and broken arrows show positive to negative peak directions of the anomalous regions. Solid arrows show clockwise rotations. Broken arrows show anticlockwise rotations. R1-R10 indicate the selected regions. Lows are hatched.

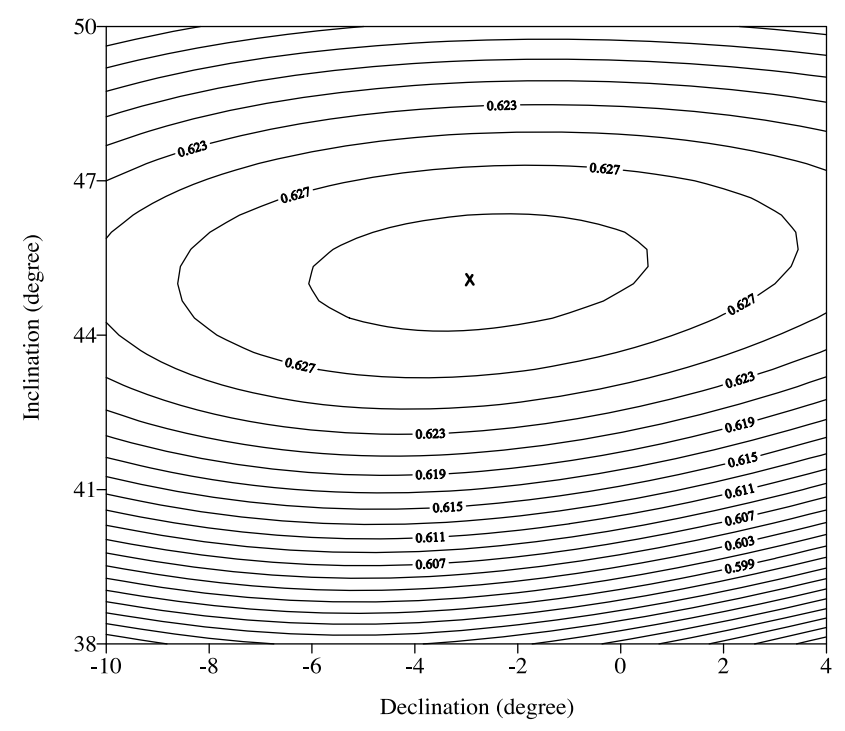

Fig. 5. Contour map of correlation coefficient $(r)$ for region 1 in the aeromagnetic anomaly map (Fig. 9).

Eq. (5), the amplitude function of the analytic signal is

$$
|A(x, y)|=\sqrt{\left(\frac{\partial T}{\partial x}\right)^{2}+\left(\frac{\partial T}{\partial y}\right)^{2}+\left(\frac{\partial T}{\partial z}\right)^{2}} .
$$

\section{Synthetic Example}

The method was tested with the magnetic anomalies of three magnetized models that closely resemble each other (Table 1) and which were produced using a body magnetization with $80^{\circ}$ declination and $50^{\circ}$ inclination angles. For this purpose, $7 \%$, in terms of $32 \mathrm{~km}(\mathrm{X}=\mathrm{Y}$ distance) random error was added to the $\mathrm{X}$ and $\mathrm{Y}$ locations of the anomalies. Magnetic anomaly of the model was calculated with a computer program using the Goodacre's (1973) algorithm. Figure 2(a) shows the magnetic anomalies, including the $7 \%$ random error. The contour map of the correlation coefficient $(r)$ for the error percentage is given in Fig. 2(a). The estimated declination and inclination angles of the body
Table 2. Results of correlations of the selected ten regions in the study area calculated from the aeromagnetic anomalies (Fig. 3).

\begin{tabular}{ccc}
\hline Region no & $\begin{array}{c}\text { Estimated directions of body magnetization } \\
\text { Declination } \\
\text { (degree) }\end{array}$ & $\begin{array}{c}\text { Inclination } \\
\text { (degree) }\end{array}$ \\
\hline 1 & -3 & 45 \\
2 & 19 & 49 \\
3 & 153 & 44 \\
4 & -16 & 44 \\
5 & 150 & 57 \\
6 & -174 & 39 \\
7 & -44.5 & 68.4 \\
8 & -48 & 41 \\
9 & 87 & 32 \\
10 & 82.5 & 43 \\
\hline
\end{tabular}

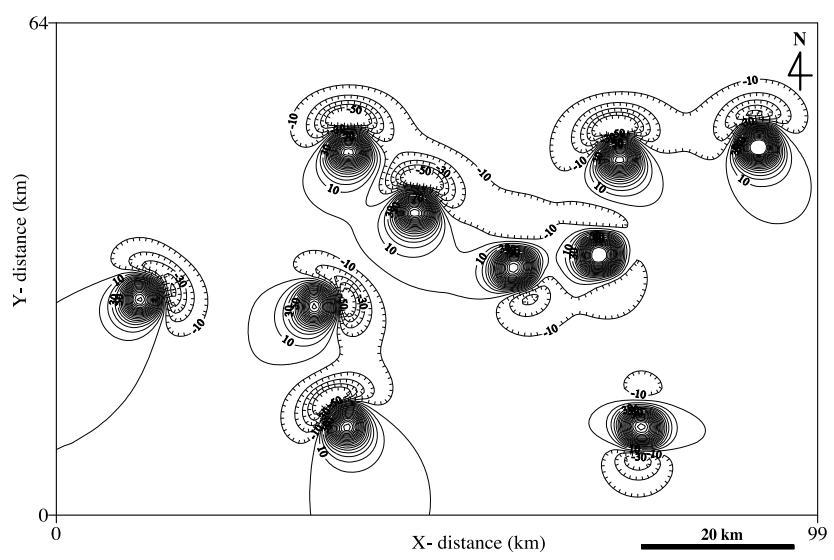

Fig. 6. Synthetic magnetic anomaly map of prismatic shaped models with dimensions of $4 \times 4 \times 2 \mathrm{~km}$. Calculated declination and inclination angles (Table 2) were used.

magnetization for the $7 \%$ error are $77^{\circ}$ and $54.5^{\circ}$, respectively (Fig. 2(b)).

\section{Field Example}

Figure 3 shows the location of an area in northern Central Turkey, where the method is applied to the residual total aeromagnetic anomalies (Fig. 4). The aeromagnetic data of the study region, gridded at $2.5-\mathrm{km}$ intervals, were obtained from the General Directorate of Mineral Research and Exploration (MTA) of Turkey. Flight lines distances vary from each other at distances of between 1 and $2 \mathrm{~km}$. The spacing between the sampling intervals is approximately $70 \mathrm{~m}$, at a mean terrain clearance of $600 \mathrm{~m}$ from the ground surface. We subsequently carried out the International Geomagnetic Reference Field (IGRF) correction on the gridded data utilizing Baldwin and Langel's (1993) algorithm for the year 1982.5 (October 1982). The total residual aeromagnetic intensity map (Fig. 4) was contoured with 50-nT intervals after the removal of the IGRF.

The residual aeromagnetic map is dominated by many anomalies, mostly disoriented from the N-S direction, implying the presence of remanent magnetization. Ten selected anomalies were constrained into small sizes so to cover their positive and negative anomaly couples, and they are labelled from R1 to R10 in Fig. 4. Their directions of magnetization were then calculated using the correlation 


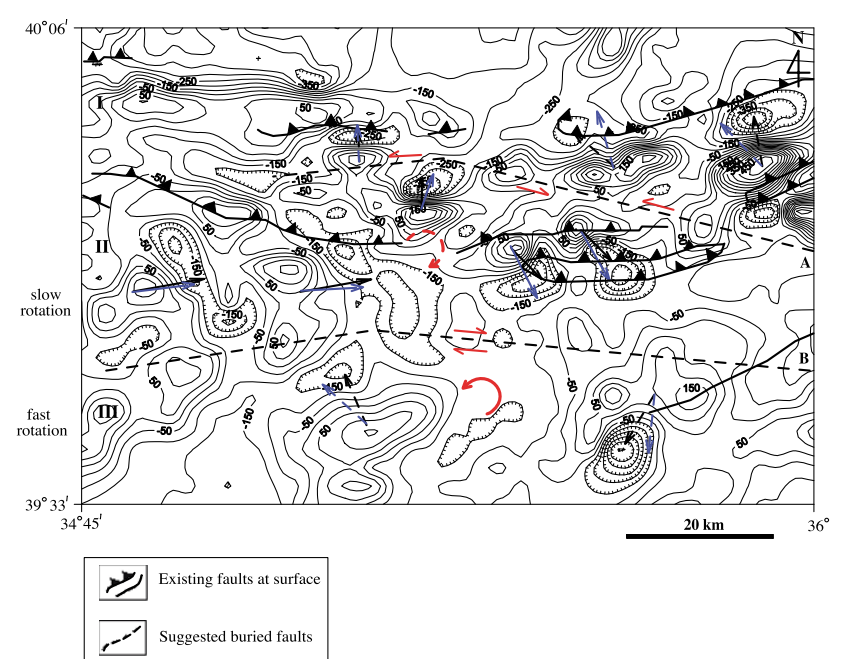

Fig. 7. Aeromagnetic anomaly map of the study region. Lows are hatched. Faults observed at the surface are overlaid. Solid and broken black arrows are present. Solid blue arrows show calculated clockwise rotations; broken blue arrows show calculated anticlockwise rotations. Broken lines labeled with A and B show possible locations of buried faults resulting from the block rotations. Regions I, III and II are rotating anticlockwise and clockwise directions with different speeds, respectively. Red arrows indicate main movements of the suggested faults and blocks I, II and III.

coefficient equation $(r)$ given in Eq. (1). Figure 5 shows the correlation contour map of region 1 . The estimated inclination and declination angles of the body magnetization for the ten regions are given in Table 2.

Anomalous regions 1, 4, 6, 7, and 8 demonstrated negative declination angles varying from $-3^{\circ}$ to $-174^{\circ}$, while anomalous regions $2,3,5,9$, and 10 demonstrated positive declination angles varying from $19^{\circ}$ to $153^{\circ}$. Negative and positive declinations are projected in Fig. 4 from the peak to the trough of the anomalies with broken and continuous arrows, respectively.

The corresponding synthetic map of the anomalies was generated to compare the real map and the synthetic map. Prismatic shaped models were used with dimensions of $4 \times 4 \times 2 \mathrm{~km}$. Calculated declination and inclination angles were used to produce the synthetic magnetic anomalies (Fig. 6). The orientations of the negative and positive peaks of the synthetic anomalies resemble that of the aeromagnetic anomalies shown in Fig. 4.

\section{Discussion and Conclusions}

In the test cases reported here, we have demonstrated that our method of estimating the direction of the magnetization was succesful. The method was also tested with three close anomalies. When a 7\% random error introduced into the coordinates of the three close anomalies, the declination and inclination angles of the body magnetization were estimated at $77^{\circ}$ and $54.5^{\circ}$, respectively. The test cases produced successful results in terms of the magnetic to magnetic correlation using the correlation coefficient equation $(r)$. The method was applied to the aeromagnetic anomalies (Fig. 4) of a faulted area in northern Central Turkey (Fig. 3).

Application of this method to the ten disoriented, selected shaped anomalous regions of the aeromagnetic anomalies

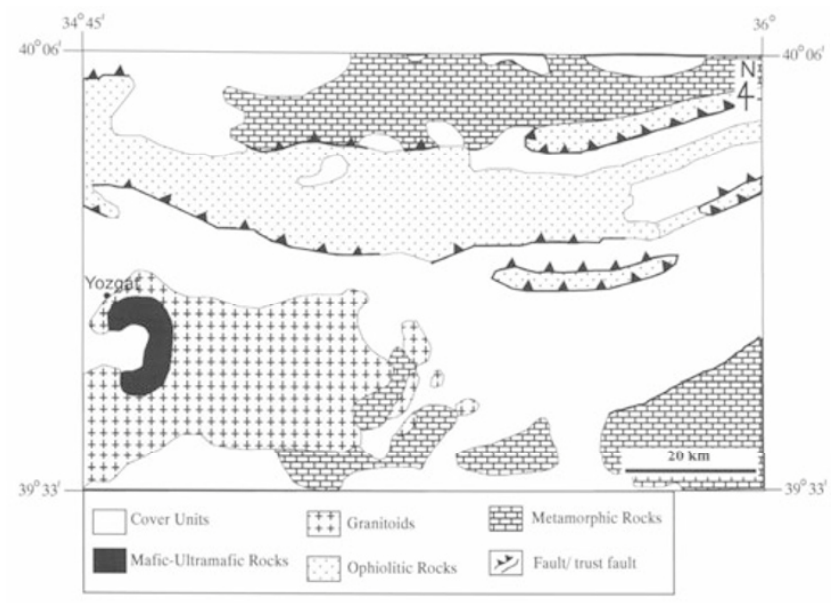

Fig. 8. Geology map of the study region (after Bingol, 1989).

of a tectonically active region in northern Central Turkey indicated clockwise and anticlockwise block rotations. The clockwise rotations ranged between $19^{\circ} \mathrm{E}$ and $153^{\circ} \mathrm{E}$, and the anticlockwise rotations ranged between $-3^{\circ}$ and $-174^{\circ}$. Anticlockwise rotations appear to occur in the north and south, while the clockwise rotations appear to occur in the middle of the region. Based on these results, we suggest that buried faults are present in the region along the E-W direction, parallel to the main fault trend (Fig. 7). The area can be divided into three blocks (I, II and III) in terms of the rotations of the selected individual anomalies. On the basis of the rotations of the anomalous bodies, the study area has been rotating in the anticlockwise (blocks I and III) and clockwise (block II) directions under the effect of the African Block. In the northern hemisphere, magnetic anomalies of a dipolar source bodies can have a positive peak in the south and a smaller negative peak in the north. If the bodies causing the magnetic anomalies gained their magnetization during a reversed magnetization time, smaller positive peaks can be present. Our investigation of the eight anomalies selected for study indicate that the negative peaks of anomaly numbers $1,2,3,4,5,6,7$, and 8 are smaller than their positive peaks. Two anomalies, numbers 9 and 10, appear have equal-sized negative and positive peaks. These results indicate that the magnetized bodies in most of the area gained their magnetization during a normal polarity time.

The simplified geological map of the region (Bingol, 1989) (Fig. 8) shows faults that are approximately elongated in the E-W direction. Metamorphic rocks in the north and south of the region are observed that produce a magnetic anomaly at low to medium amplitude. These metamorphic rocks in the north are of Palaeozoic-Triassic period (Bingol, 1989) and are found as a deformed complex consisting of essentially ophiolitic masses, shallow and deep sea sediments, and submarine volcanics. It is therefore possible to suggest that ophiolites carry magnetized bodies and that the metamorphic formations gained their magnetization during the metamorphism stage. In the south positive sharp anomalies may be caused by gabbroic intrusions beneath the granitic formations seen in this area. 
Gabbroic formation outcrops are present in the western extremity of the area. The thick layer of metamorphic rocks in the north behaves as a rigid barrier. This barrier is similar to the one present in the Marmara Sea that intercepts the movement of the North Anatolian Fault at depth (Ates et al., 2003). A fault zone to the south of the metamorphic rocks was formed, allowing clockwise and anticlockwise rotations within the westward wrenching of the global lithosphere, as described by the new mobilistic system (Storetvedt, 2003).

Acknowledgments. The aeromagnetic and gravity data of the study region were obtained from the General Directorate of the Mineral Research and Exploration (MTA) of Turkey. We would like to thank reviewers Drs. Yukari Kido and M. N. Dolmaz for their helpful criticism. We also would like to extend our thanks to the editor Dr. Hidefumi Tanaka for his excellent editorial work on this manuscript and critically reading it, which improved the paper. This research was supported by the Turkish Scientific Research Council (TUBITAK) (project no: 102Y121) and Ankara University, Scientific Research Projects (project no: 2000705050).

\section{References}

Ates, A., T. Kayiran, and I. Sincer, Structural Interpretation of the Marmara Region, NW Turkey from aeromagnetic, seismic and gravity data, Tectonophysics, 367, 41-99, 2003.

Baldwin, R. T. and R. Langel, Tables and Maps of the DGRF 1985 and IGRF 1990, International Union of Geodesy and Geophysical Association of Geomagnetism and Aeronomy, IAGA Bull., 54, 158, 1993.

Baranov, V., A new method for interpretation of aeromagnetic maps: Pseudogravity anomalies, Geophysics, 22, 359-383,1957.

Bilim, F. and A. Ates, A computer program to estimate the source body magnetization direction from magnetic and gravity anomalies, Comput. Geosci., 25, 231-240, 1999.

Bilim, F. and A. Ates, An enhanced method for estimation of body magnetization direction from pseudo-gravity and gravity data, Comput. Geosci., 30, 161-171, 2004.

Bingol, E., 1/2,000,000 scale geologic map of Turkey. Publication of the Mineral Research and Exploration (MTA) of Turkey, Ankara, 1989.

Blakely, R. J., Potential Theory in Gravity and Magnetic Applications, 441 pp., Cambridge University Press, Cambridge, 1995.

Blakely, R. J. and R. W. Simpson, Approximating edges of source bodies from magnetic or gravity anomalies, Geophysics, 51, 1494-1498, 1986.
Buyuksarac, A., D. Jordanova, A. Ates, and V. Karloukovski, Interpretation of the gravity and magnetic anomalies of the Cappadocia Region, Central Turkey, Pure Appl. Geophys., 162, 2197-2213, 2005.

Goodacre, A. K., Some comments on the calculation of the gravitational and magnetic attraction of a homogeneous rectangular prism, Geophys. Prosp., 21, 66-69, 1973.

Gursoy, H., J. D. A. Piper, O. Tatar, and L. Mesci, Palaeomagnetic study of the Karaman and Karapinar volcanic complexes, central Turkey: neotectonic rotation in the south-central sector of the Anatolian Block, Tectonophysics, 299, 191-211, 1998.

McClusky, S., S. Balassanian, A. Barka, C. Demir, S. Ergintav, I. Georgiev, O. Gurkan, M. Hamburger, K. Hurst, H. Kahle, K. Kastens, G. Kekelidze, R. King, V. Kotzev, O. Lenk, S. Mahmoud, A. Mishin, M. Nadariya, A. Ouzounis, D. Paradissis, Y. Peter, M. Prilepin, R. Reilinger, I. Sanli, H. Seeger, A. Tealeb, M. N. Toksoz, and G. Veis, Global positioning system constraints on plate kinematics and dynamics in the eastern Mediterranean and Caucasus, J. Geophys. Res., 105, 5695-5719, 2000.

Meyer, P. L., Introductory Probability and Statistical Applications, 339 pp, Wesley Publishing Co., Massachusetts, Addison, 1965.

Piper, J. D. A., H. Gursoy, and O. Tatar, Paleomagnetism and magnetic properties of the Cappadocian ignimbrite succession, central Turkey and neogene tectonics of the Anatolian collage, J. Volcan. Geoth. Res., 117, 237-262, 2002.

Roest W. R. and M. Pilkington, Identifying remanent magnetization effects in magnetic data, Geophysics, 58, 653-659, 1993.

Roest, W. R., J. Verhoef, and M. Pilkington, Magnetic interpretation using the 3-D analytic signal, Geophysics, 57, 116-25, 1992.

Rotstein, Y., Counterclockwise rotation of the Anatolian block, Tectonophysics, 108, 71-79, 1984.

Sanver, M. and E. Ponat, Kirsehir ve dolaylarina iliskin paleomanyetik bulgular. Kirsehir Masifinin rotasyonu, Istanbul Yerbilimleri, 2, 231238, 1981.

Saribudak, M., M. Sanver, A. M. C. Sengor, and N. Gorur, Paleomagnetic evidence for substantial rotation of the Almacik flake within the North Anatolian Fault Zone, NW Turkey, Geophys. J. Int., 102, 563-568, 1990.

Storetvedt, K. M., Global Wrench Tectonics, 397 pp, Fagbokforlaget, Norway, 2003.

Zeitz, I. and R. G. Henderson, A preliminary report on model studies of magnetic anomalies of three-dimensional bodies, Geophysics, 21, 794814, 1956.

F. Bilim (e-mail: fbilim@cumhuriyet.edu.tr) and A. Ates 